\title{
O conhecimento como modo de ser do ser humano na Fenomenologia Hermenêutica
}

\author{
Knowledge like a man's kind of being in the Hermeneutical \\ Phenomenology
}

Cezar Luís Seibt*

recebido: 09/2014

aprovado: $12 / 2014$

\begin{abstract}
Resumo: As reflexões sobre a natureza do conhecimento conduzem, na tradição, a dicotomias, tais como a separação entre o sujeito e objeto, que exigem uma teoria que reaproxime os dois elementos. As teorias do conhecimento são elaborações que procuram fundar e justificar essa relação. Buscamos mostrar que Heidegger, com a sua fenomenologia hermenêutica, na insistência em torno da faticidade e do serno-mundo, apresenta uma forma de entender o fenômeno do conhecimento a partir do reconhecimento da condição originária do ser humano, da sua finitude. Neste pensamento dá-se a superação da dicotomia e da exigência de sempre novas fundamentações exteriores ao próprio fenômeno.
\end{abstract}

Palavras-chave: Fenomenologia, Hermenêutica, conhecimento, ser-no-mundo.

Abstract: The reflections about the nature of knowledge lead, in the tradition, to dichotomies, such as the separation between subject and object, which requires a theory that re-approach the two elements. The theories of knowledge are elaborations that seek to found and justify this relationship. We seek to show that Heidegger, with his hermeneutic phenomenology and the insistence on facticity and being-in-the-world, presents a way to understand the phenomenon of knowledge from the recognition of the original man's condition, his finitude. In this thought he overcomes the dichotomy and the demand for ever new external foundations for the phenomenon itself.

Keywords: Phenomenology, Hermeneutic, knowledge, beingin-the-world.

\footnotetext{
* Doutor em Filosofia. Professor de Filosofia da Educação da UFPA (Campus Cametá e Programa de Pós-Graduação em Educação). Em@il:celuse@ufpa.brecezluse@yahoo.com.br Problemata: R. Intern. Fil. v. 5. n. 2 (2014), p. 302-317 e-ISSN 2236-8612 doi:http://dx.doi.org/10.7443/problemata.v5i2.20671
} 


\section{Considerações Introdutórias}

No âmbito da reflexão sobre o conhecimento há, normalmente, a exigência de uma erudição e de uma complexidade que podem acabar dificultando a visão do fenômeno mesmo do conhecer. $\mathrm{O}$ exercício fenomenológico pode ser um trabalho de retorno para a simplicidade da questão, no sentido de voltar ao solo fático donde ele brota. As teorias se perdem em longas e abstratas argumentações que se afastam cada vez mais dos objetos eles mesmos. Nesse emaranhado de argumentações a discussão acaba ficando restrita ao conteúdo da consciência ou a critérios de validade ou invalidade. Resultam teorias que procuram explicar o fenômeno do conhecimento.

A reflexão que Heidegger realiza tem antecedentes na crise entre as noções de 'história' e 'teoria', que emerge a partir da obra de Dilthey, como crítica ao paradigma fundado "sobre a tripartição sujeito-objeto-método (eu, a coisa, o meu modo de considerá-la)" (D'AGOSTINI, 2003, p. 39). O modelo da ciência que se caracteriza pela razão calculante, instrumental e classificatória contribui para o domínio que o ser humano pode impor às coisas, mas não dá conta dos problemas da filosofia. As ciências humanas, sobretudo a filosofia, não pretendem abdicar do espírito crítico, de uma racionalidade não instrumentalizada, do horizonte não-científico da cultura humana, da vida, enfim. Também em Husserl temos o esforço por superar as idealizações teóricas e objetivas, para restabelecer as condições para o encontro com as coisas elas mesmas, para o pré-científico mundo da vida. Heidegger participa deste programa, tentando radicalizá-lo para alcançar efetivamente a faticidade.

Kierkegaard se opõe às subsunções da singularidade na universalidade. Pensa que "o que excede a existência é teoricamente frio e irrelevante; de outra parte, a existência mesma não pode jamais constituir-se como objeto 'teórico', separado de quem a habita, a vive e é por ela compenetrado“ (D’AGOSTINI, 2003, p. 133). Há uma convicta e nítida defesa da liberdade do homem, da impureza, da vivência antes da teoria; uma valorização da singularidade e dos elementos históricos e contingentes da vida humana.

Neste sentido Heidegger pergunta: "o que é, em geral, conhecer?" (2004, p. 87) e não quais as justificativas para a 
verdade de um conhecimento ou suas fontes. Isso não significa que tal investigação das fontes e critérios não seja importante, mas que há que determinar ainda antes o que seja propriamente o conhecer. E a primeira constatação é de que o conhecer é intencional. $\mathrm{O}$ conhecimento é sempre conhecimento de alguma coisa. Sendo o conhecer sempre conhecimento de algo, uma pergunta que segue é: "a que se dirige o conhecer?" (2004, p. 87). Com isso não se pensa em determinar o tipo de objetos conhecíveis ou não conhecíveis, mas sim o "por meio de que se caracteriza tudo isso" ou, dito de outra forma, "pelo a que como tal" (2004, p. 87). Para responder, Heidegger indica que é preciso partir do próprio fenômeno e, portanto, seguir o "processo de um conhecimento concreto tal como nos é conhecido ou habitual, como algo cotidiano" (2004, p. 87). Ao dirigir o olhar para o entorno, encontram-se janelas, mesas, alunos... e não algo como conteúdos da consciência, nem captação de sensações ou conceitos. O olhar tem em vista a janela mesma, não suas qualidades específicas e particulares, não um conceito de janela e nem a janela enquanto conteúdo da consciência.

Pode parecer que Heidegger dirige aqui a discussão para o ingênuo e simples. E, como ele diz, isso até é verdade. No entanto é

decisivo em vista das construções confusas da teoria do conhecimento. Armada de uma teoria, esta, por assim dizer, se lança cega ao fenômeno do conhecimento e o explica, em lugar de deixar em paz a teoria e voltar o olhar de uma vez para o que é pois que se deve colocar como base da 'explicação'. Em vista das teorias que circulam, a primeira constatação primitiva e sobretudo sua fixação são decisivas: o 'a que', o próprio ente (2004, p. 87 e 88$)$.

O olhar não se dirige primeiro para alguma representação, mas diretamente para algo enquanto algo, assim como se dá num contexto significativo. Não se inicia com uma justificativa, mas simplesmente vê-se alguma coisa. Mas esse ver não pode sempre fiar-se na presença física do objeto em questão para poder obter crédito. Como se vai então saber se o objeto se comporta de acordo com aquilo que é dito dele? Heidegger afirma que "na medida em que a coisa da que tenho conhecimento e acerca da qual falo não comparece necessária e 
constantemente de modo imediato, e quando eu mesmo não estou na própria coisa, nosso conhecimento e nosso discurso em último termo sempre requerem, em ampla medida, da comprovação" (2004, p. 91). Se aquilo que se intenciona no discurso não está presente, pois presente temos somente o conceito, introduz-se a necessidade da justificação. $\mathrm{O}$ conhecimento de algo e o discurso precisam mostrar suas credenciais para que sejam acreditados e, portanto, tem de "deixar-se controlar pela própria coisa" (HEIDEGGER, 2004, p. 91).

O discurso fala da coisa, mas pode fazê-lo de modo totalmente vazio, tornar-se um representar vazio. Muito conhecimento e discurso que se conservam como saber podem tornar-se um saber e discurso vazios e, por isso, exigem legitimação. Essa legitimação não pode dar-se a partir do referido conhecimento, mas vai exigir outro conhecimento que o justifique e assim ao infinito. Ou seja,

\begin{abstract}
Se a legitimidade de um conhecimento somente se dá quando ele mesmo é conhecido em um segundo conhecimento, então esse conhecimento requer novamente demonstração da sua legitimidade e assim ao infinito. E o primeiro conhecimento específico, o autêntico conhecimento específico, jamais chegaria a legitimar-se, porque previamente sempre seria necessário ir até o infinito para conhecer em sua legitimidade o conhecimento da legitimidade do próprio conhecimento (2004, p. 93).
\end{abstract}

Para a situação fenomenológica, a legitimidade do conhecimento não se constata posteriormente, através de outro conhecimento e assim ao infinito, mas a evidência se "faz visível em e mediante a realização intencional da própria identificação e, para este ato" (2004, p. 93). A intencionalidade sugere isso: conhecimento é sempre conhecimento de algo. Não há conhecimento que não seja conhecimento de algo, como se houvesse uma entidade separada, autônoma em relação ao conhecido. Um olho que olha para o conhecimento é já separação. De acordo com o princípio fenomenológico, o conhecer se constitui enquanto conhece algo. Em termos de fundamentação, estamos diante de um conhecer (do conhecer) sem olho externo, sem a distância da teoria, sem a prévia separação entre sujeito e mundo. Neste programa Heidegger 
retorna para a condição humana e, neste caso, "em lugar de descrever a essência do ser humano, descreve-se o ser (a existência) do ser humano" (STEIN, 2002, p. 180).

\section{Existência como compreensão}

Quando Heidegger propõe uma compreensão do ser do ser humano e também do conhecimento a partir do originário ser-no-mundo, está trabalhando na superação das objetificações e cristalizações da tradição metafísica. A filosofia não pode ser feita a não ser com as possibilidades e limites da razão historicamente situada, enraizada na lida compreensiva com o mundo. Não pode, sem transgredir os limites da condição fática, mundana, apelar para razões externas, para silogismos que exigem demonstração ao infinito, que são posições teóricas que perdem o solo a partir de onde se projetam. Esse solo a partir de onde as posições teóricas se desenvolvem é um modo de ser prático, existencial, circunstanciado no espaço e no tempo. É no ' $D a$ ' (aí) que estão as possibilidades e limites. Qualquer extrapolação do 'aí', embora legítima e até necessária, é feita a partir do 'aí'. Não é um lugar infinito, nem uma posição teórica, mas um modo prático de ser que precisa ser posto como ponto de partida de toda investigação. Esse 'aí' compreende a si mesmo sem poder sair do 'aí'. Aqui encontramos a questão hermenêutica da circularidade. $\mathrm{Na}$ abertura do ' $\mathrm{Da}$ ' o Dasein precisa tornar-se acessível para si mesmo, mas não tem nenhuma posição externa ou teórica que possa servir de apoio para esse empreendimento. A abertura só é abertura pelo que está 'contido' na abertura. Os entes estão no ser, estão na abertura. Os entes se constituem nessa abertura do ser, enquanto o ser, a abertura, se constitui a partir da relação com os entes. Por isso Heidegger pode dizer que a relação cotidiana é uma relação decaída, não no sentido negativo, mas já sempre presa na própria relação. $\mathrm{O}$ decaído tem a ver com o fato de que a abertura que se dá na relação já não vê a si própria, mas vê somente o que comparece dentro da abertura do ser.

Esse novo contexto compreensivo de Heidegger permite que ele possa fazer uma inversão da tradição: a verdade é o lugar da proposição e não a proposição o lugar da verdade (Cf. HEIDEGGER, 1998, § 44). A verdade da proposição é um 
fenômeno derivado, fundado na verdade da intuição, na abertura originária do Dasein. A verdade está originariamente no modo de ser do ente que está na e é a abertura, e só secundariamente na proposição. Para sair desse pré-juízo tradicional que é tomado por evidência, Heidegger propõe a lógica filosofante com a tarefa de perguntar se "esta determinação preliminar e indiscutida da verdade é algo último e fundamento em si mesmo, ou se ela não passa de um prejuízo, mesmo que um prejuízo necessário e por que é um prejuízo necessário" (2004, p. 105). Uma pergunta mais radical, que vá às raízes da interpretação tradicional da verdade, poderá despertar novamente o próprio filosofar. Como diz Heidegger, "primeiro o filosofar tem que despertar e confrontar-se com seus grandes e produtivos adversários para que, neste confronto, ele mesmo cresça e fixe a linha das coisas elementares. Elementares tanto no sentido do simples como do elementar-eruptivo" (2004, p. 106).

A lógica filosofante deverá poder mostrar e se libertar dos limites em que a lógica tradicional se encontra. A verdade não será simplesmente a verdade da proposição ou, dito de outra forma, não será o juízo o lugar da verdade, mas a própria verdade será a condição prévia e originária para que a verdade do juízo possa acontecer. A proposição só é possível dentro do âmbito da verdade, da verdade enquanto um descobrir, uma abertura, mostra Heidegger (cf. 2004, p. 113). Aquilo que é unido ou separado na expressão lingüística do juízo depende do fenômeno estrutural prévio da verdade. O poder falar algo, a elaboração da proposição supõe já sempre a abertura do mundo, abertura que é já sempre conhecimento de algo, ou seja, o ente comparece já dentro de um contexto significativo em que está aberto o seu "para quê" (cf. 2004, p. 120).

Heidegger afirma que o conhecimento é tradicionalmente entendido como

[...] conhecimentos acabados e isolados, formulados em anunciados, proposições ou juízos; juízos, compostos de conceitos, e articulações de juízos que são silogismos. Nestes, e no que significam, subjazem estruturas que se atém a leis. Os juízos se levam a cabo mediante o apreender representativo ou sem mais, intuitivo; por isso há neles verdade e objetividade. Os conceitos desses objetos há que obtê-los de modo autêntico, ou seja, há que extraí-los dos objetos mesmos e garanti-los a partir dos objetos mesmos (2007, p. 105).

Problemata: R. Intern. Fil. v. 5. n. 2 (2014), p. 302-317 e-ISSN 2236-8612 
Normalmente se separa o conhecer da sua 'mundanidade', se separa a consciência e o mundo dos entes. $\mathrm{O}$ conhecimento autêntico tem a ver com o retorno para o 'mundo', para o modo de ser em que consciência e mundo estão simbioticamente unidos. Antes da teorização que separa e diferencia, há um modo de ser em que há 'lida compreensiva', uma relação em que já sempre há compreensão, abertura, sentido. Na expressão de Heidegger, "falando, compreendendo, eu sou, enquanto existência, trato compreensivo. Meu ser no mundo não é outra coisa que este mover-se já compreensivo nestes modos de ser" (2004, p. 122). Não há originariamente um conhecimento puro, plano, um puro conceber, mas sim uma lida compreensiva. Vivemos numa compreensão do entrar, sair, iluminar, escrever, assim por diante. Há um contexto remissivo de significações que está construído a partir do 'para que serve' algo. Algo que me comparece já sempre comparece enquanto este ou aquele ente, um copo enquanto copo, um giz enquanto giz, sem que tenha de fazer algum esforço investigativo para determinar o ser deste ente. $\mathrm{O}$ ente comparece enquanto algo. Para Heidegger, há uma conduta primária, que ele assim descreve:

\footnotetext{
Numa concepção plana das coisas mais naturais que capto de modo não temático, mas através do ter a ver com, não vejo, por exemplo, uma coisa branca que, através de algum tipo de manipulação, possa tornar-se um giz, senão que de entrada vivo já no contexto do 'para quê', me detenho já num determinado mundo circundante que está orientado a uma conduta e um procurar determinados, e a partir deste procurar e desta conduta entendo essa coisa como giz (2004, p. 123).
}

Nossa existência é compreensiva. Numa nota Heidegger diz que o compreender é um modo fundamental de ser do existir que “detendo-se cada vez já no 'de onde' da interpretação (no 'algo enquanto algo'), se dirige a um estar presente, abrindo-o quando retorna enquanto isso ou aquilo" (2004, p. 125). Continuando, o autor afirma que o existir compreensivo não está primeiramente dirigido para os objetos concretos e nem para os conceitos gerais, mas vive no mundo circundante imediato. Desse modo, a existência é significativa em si mesma e pode, assim, "viver em significados e pode expressar-se como tal" 
(2004, p. 126). Esse modo fundamental de ser do existir, Heidegger caracteriza assim:

O 'ter a ver com' e o 'tratar com' não surgem em
absoluto na medida em que eu comece a ter a ver com
algo, senão que eu somente posso começar com isso na
medida em que minha existência está determinada já
primariamente como existência que trata com e que
procura. A existência é procuradora qua existência, e o
único que pode educar-se são certas tendências e graus
de precisão e habilidade de procurar $(2004$, p. 128$)$.

Previamente ao enunciado, a existência já está na compreensão e no descobrimento. A tematização que se realiza no enunciado se move no prévio compreender. Essa abertura primária disponibiliza as possibilidades de uma posterior teorização. As possibilidades abertas podem ser educadas e precisadas através da conduta teórica e podem, inclusive, aparentar não ter conexão com um solo originário prático, compreensivo. Por isso a hermenêutica do Dasein e a destruição da metafísica que o autor pretende realizar, conforme anunciado no início de Ser e Tempo.

O esquecimento do solo originário, do saber no trato, inexplícito e atemático, se realiza no enunciado teórico 'apresentativo', que torna presente a coisa neste ou naquele modo em que ela se mostra. Tornar presente algo só é possível "com base num voltar a ocultar o giz (no exemplo de Heidegger) como um 'com quê' do 'ter a ver com"' (2004, p. 131). Ou seja, a proposição tem o poder de mostrar ou encobrir o descoberto na abertura ao fazer a passagem da lida, do descobrir primário do ente para o teórico. A teorização providencia o esquecimento de que a determinação categorial é um fenômeno derivado. Heidegger (Cf. 2004, p. 133) também alerta para o fato de que não se compreende os fenômenos da enunciação, da mostração, da linguagem, de forma autêntica e na sua raiz se não se atenta para o lugar originário onde eles se fundam. Normalmente, permanece-se numa análise cega das estruturas externas ou internas ao próprio discurso, o que obstaculiza a compreensão do fenômeno da linguagem, da enunciação, do sentido e do próprio interpretar.

Na cotidianidade, no modo de ser da decaída, esquece-se o modo de ser do Dasein enquanto possibilidade, um ente para o qual importa seu próprio ser, para quem seu ser está em jogo no 
existir. Esconde-se o fato do conhecimento nascer da existência fática e de sua cotidianidade, e que a compreensão humana só é possível a partir do tempo. Por isso é necessário analisar o ser a partir das determinações temporais.

\section{Conhecimento como modo de ser do Dasein}

O parágrafo 20 de Prolegômenos para um História do Conceito de Tempo (2007) é um dos mais explícitos em relação ao problema do conhecimento. Nele Heidegger mostra em que sentido o conhecer é um modo derivado de ser-em do Dasein e procura mostrar como compreende as tradicionais tentativas de apresentar a questão. O parágrafo intitula-se: 'O conhecer como modo derivado de estar-sendo-em do Dasein'.

Heidegger nota no início que a relação do homem com o mundo foi normalmente caracterizada pela tradição através do conhecer. Isso fica claro a partir da definição grega de ser humano enquanto 'animal racional', onde a diferença específica em relação ao gênero animal é a racionalidade, o pensamento. Em Descartes, na modernidade, a razão também ocupa o centro das atenções. O primeiro princípio indubitável que Descartes encontra se expressa numa relação entre ser e pensar: 'penso, logo sou'. Sou, existo, pelo fato de pensar. Pelo pensamento tenho alguma garantia de que sou. Ou seja, no modo de um "estar no mundo que seja conhecê-lo" (HEIDEGGER, 2007, p. 201). A garantia vem da compreensão de que o "ser do mundo não é senão a objetividade da apreensão da natureza que se obtém através da medição e do cálculo" (HEIDEGGER, 2007, p. 227).

A matemática e a física tornam-se o critério da verdade, da correspondência do conhecimento com o conhecido. A certeza é o ideal do conhecimento. Inclusive, como diz Heidegger, a "relação de sujeito com o objeto se concebeu de entrada enquanto relação de conhecimento, para depois, mais tarde, se incorporar o que se chama de relação prática" (2007, p. 201).

Heidegger irá mostrar como essa relação é habitualmente compreendida e o que significa esse dualismo sujeito e objeto na questão tradicional do conhecimento. Em primeiro lugar, quando se fala nesta relação entre mundo e consciência se supõe 
que há sempre já um ente prévio que será conhecido pela consciência, um ente natural a ser conhecido. Há, portanto, um dentro e um fora. $\mathrm{O}$ 'dentro', como assinala Heidegger, é o lugar onde está o conhecimento que, afinal, deve estar em algum lugar e estar livre de pressupostos. $\mathrm{O}$ conhecimento sobre o ente não está no ente conhecido, mas 'dentro' do ente que conhece. E, diz ele:

\begin{abstract}
Quanto mais univocamente se estabelece que o conhecer está primária e verdadeiramente 'dentro', tanto mais se crê estar avançando sem pressupostos na questão acerca da essência do conhecimento e na caracterização da relação de ser na qual o sujeito se situa com relação ao objeto. Assim surge logo a pergunta: como consegue sair o conhecer, que segundo seu ser está dentro, no sujeito, da sua 'esfera interior' para chegar à 'outra esfera, exterior', do mundo? (2007, p. 202).
\end{abstract}

Nessas afirmações aparece o dualismo no qual a questão teórica do conhecimento se move. Trata-se, na tradição, de mostrar como esta relação entre um 'dentro' e um 'fora' é possível, justificá-la, fundamentá-la. Nela se toma posição em relação a um ou outro extremo dos pólos, mas não se alcança o modo originário no qual o conhecimento acontece. $\mathrm{O}$ que ocorre é que se salta e ignora o fenômeno do ser-no-mundo. Parte-se já sempre do ponto de vista teórico e não de uma observação fenomenológica do fenômeno. Von Herrmann, interpretando o texto do seminário de 1919 (A idéia da filosofia e o problema das visões de mundo), sobretudo a afirmação de Heidegger em relação ao problema da fundamentação, na qual ele diz que "tudo isso é interpretação errônea, ruim, uma distorção da visão pura da vivência" (HEIDEGGER, 1999, p. 71), diz que

A interpretação da vivência do mundo circundante feita com o conhecer teórico e fenomenológico é 'ruim', porque é interpretação conduzida erroneamente através de um pensamento que tem sua origem numa reflexão teórica que não foi extraída da vivência do mundo entorno (VON HERRMANN, 2000, p. 35).

Merece consideração o fato de que na posição teórica se oculta o ser-no-mundo. Na teorização acontece uma modificação no modo de ser-no-mundo do Dasein. Mas então,

Problemata: R. Intern. Fil. v. 5. n. 2 (2014), p. 302-317 
como é o ser-no-mundo do Dasein antes da modificação que acontece com o comportamento teórico?

Heidegger mostrará como antes da teorização o Dasein já está sempre numa relação prática no mundo. Não há primazia do prático sobre o teórico ou vice-versa, mas o modo originário, a partir do qual a teorização é possível, é uma relação préteórica, pré-científica, prática ou, em outras palavras, compreensiva ou pré-compreensiva. Há um modo de ser que não é comparável ao modo como as pedras, as plantas ou os animais são. É um modo de ser que, ao se encontrar com outro ente, já sempre o tem dentro de um âmbito de sentido, de ordem prática, do saber o que fazer, do para que serve, da utilidade.

O Dasein já sempre é no mundo, onde mundo não é um objeto, a natureza, mas esse horizonte no qual as coisas servem, ameaçam ou causam satisfação. É ser-em, um ser que tem sempre algum contexto, entende a si e ao que comparece dentro do contexto a partir deste seu ser-em. Ele se abre nesta relação com o contexto e o próprio contexto surge desta relação. Isso tem implicações fundamentais, visto que o conhecer se dá na imanência, na finitude, no ser-em. O ser-em não é nenhum contexto privilegiado ou isolado que confere algum privilégio especial para o conhecimento. A base para o conhecimento é o já sempre estar-em ou ser-em. O conhecer, por isso, não é a posição primeira do ser humano, mas derivada e dependente das possibilidades do ser-em. Como diz Heidegger, "conhecer não é, portanto, uma atuação que se inicie num ente que ainda não 'tem' mundo, que se encontre livre de toda relação com seu mundo, senão que conhecer é sempre um modo de ser do Dasein que se dá sobre a base de seu ser-já-em no mundo" (2007, p. 203).

O não reconhecimento desta condição primária e fundamental do conhecer enquanto um modo de ser do Dasein como ser-em e que, além disso, se ocupa com processos derivados tais como a fundamentação da relação sujeito e objeto, é o problema que acompanha os esforços das teorias do conhecimento na busca de soluções satisfatórias para as dicotomias tradicionais. Não reconhecem o "conhecer em sua condição fenomênica originária" e dessa forma não partem desta "observação básica" e não a tomam "como fundamento" (HEIDEGGER, 2007, p. 203). Heidegger chama de 'falsos problemas' muitos dos problemas com que a epistemologia lida 
e mostra que "não se faz desaparecer mediante um golpe de força o problema do conhecimento, senão que, somente situando-o sobre o solo que o faz possível" (2007, p. 204). Tendo em vista o solo que torna o conhecer possível é que se poderá reconhecer e separar os 'falsos problemas', do 'problema' que realmente importa.

Heidegger enumera alguns passos no processo do conhecimento que, sempre pressupondo a abertura do ser-em, conduzem para a apreensão teórica dos entes. Essa decomposição de momentos é resumida assim:

[...] o dirigir-se cognoscente enquanto deter-se em e perceber tende ao percebido de maneira tal que o conserva, de modo que o conhecer tem no percebido, no saber sobre ele, o conhecido mesmo quando este atualmente não esteja mais diante dele. O conhecimento o conserva como se fosse propriedade sua. Isso só se pode entender caso se tenha em conta o caráter primário do Dasein enquanto 'que ser', mas não se o sujeito é algo psíquico que tem representações que guarda, das quais é preciso dar explicação de como se adéquam (HEIDEGGER, 2007, p. 206).

Há um dirigir-se que se detém diante do ente e o conserva. O ponto de partida, no entanto, é o já sempre ser-em que 'retém conservando o conhecido' e, nesta operação alcança outra relação com o ente, modificada com o conhecimento. Do dirigir-se $a$ até a retenção há uma distância que cria a postura teórica. Mas, como adverte Heidegger, "a primeira antecipa todas as demais e se mantém nelas, e é antecipadora somente porque é ser-em" (2007, p. 206). Nesta operação revela-se o já sempre estar no mundo do Dasein, diferente da separação 'dentro' e 'fora' da concepção metafísica. O Dasein, "por seu próprio sentido está sempre já 'fora', no mundo [...] que já está sempre de algum modo descoberto" (HEIDEGGER, 2007, p. 206). Dasein já tem sempre uma relação com o mundo. Mundo não lhe precisa ser acrescido, como se fosse algo externo. $\mathrm{O}$ Dasein é "um ente que está sendo no seu mundo e, ao mesmo tempo, sobre a base do mundo no qual está sendo" (HEIDEGGER, 2007, p. 254). Decorre disto que "conhecer não é senão uma maneira de estar-sendo-no-mundo, e não precisamente a maneira primária, senão um modo de ser fundado do estar-sendo-no-mundo, somente possível sob a base 
sempre de uma atuação que não é cognoscitiva" (HEIDEGGER, 2007, p. 207).

A forma como compreendemos o conhecimento, os critérios e explicações que lhe damos, não correspondem a uma objetividade ou a um elemento externo atemporal e não tem, por isso, um caráter absoluto. Somos no mundo, finitos, contingentes, históricos e a nossa relação cognoscitiva com o mundo acontece dentro desse horizonte. A abertura na qual estamos e que corresponde à ideia de mundo, antecipa o conhecimento enunciativo, o discurso apofântico, a objetificação das coisas dentro do mundo. Com isso, "toda teoria do conhecimento se enraíza numa estrutura prévia de compreensão que, por sua vez, faz parte de um modo de ser no mundo" (STEIN, 2004, p. 200). A compreensão é anterior aos processos ônticos, onde que aquilo que acontece passa por um processo explicativo.

O conhecer é um modo de ser de um ente que já sempre compreende a si mesmo e aos objetos que o cercam. Não existem verdades (proposições verdadeiras) independentemente da verdade enquanto espaço ou abertura onde o desvelamento (acompanhado pelo ocultamento) acontece. Inwood assim o expressa: "Não há proposições, significados nem teorias atemporais. Tudo isso são modos de ser do Dasein, tão históricos e temporais como ele é" (2004, p. 82).

\section{Considerações Finais}

Da falta de esclarecimento e de consideração da questão primária do ser-no-mundo surgem alguns problemas da epistemologia tradicional. As posições do idealismo e do realismo e suas variações somente são possíveis na medida em que o fenômeno do ser-em se mantém oculto. Por isso, mostra Heidegger, a fenomenologia do conhecer não coincide com nenhuma das posições tradicionais. $\mathrm{O}$ ser do conhecer repousa sobre "estruturas mais originárias do Dasein" (HEIDEGGER, 2007, p. 210). Entre estas estruturas mais originárias está o caráter de ser do próprio Dasein como verdade. Verdade, neste caso, não é predicado de um conhecimento, mas modo de ser do Dasein. 
$\mathrm{O}$ acesso aos entes, dentro desse horizonte da fenomenologia do conhecimento, se dá no próprio trato e ocupação com eles e não enquanto percepção isolada ou suspensa no ar. Sendo-no-mundo, o mundo mesmo apresenta cada coisa dentro dele. Ou melhor, a mundanidade do mundo é que permite o acontecer dos entes, o seu sentido. Somente no contexto das remissões de sentido é que o ente pode ser algo, é algo enquanto algo. Esse contexto remissivo é que se mantém escondido na manifestação do ente, na medida em que o Dasein se mantém absorvido pela ocupação com os entes disponíveis (Vorhanden). O estar-sendo-em enquanto ocupar-se entendendo de, relação primária do Dasein com o mundo e consigo mesmo, pode modificar-se na direção de um entender autônomo e teórico.

No contexto da fenomenologia do conhecimento não tem mais sentido perguntar por provas, demonstrações ou justificativas para a existência do mundo externo, afirma Heidegger (Cf. 2007, p. 269). No questionar, mundo já está pressuposto (que haja mundo - abertura de sentido - é condição para o questionar), mas o mundo não pode ser experimentado, provado ou demonstrado ao modo dos entes. A experiência do mundo é feita pelo sujeito todo, na mundanidade $\mathrm{e}$ temporalidade, não "uma anêmica coisa pensante que tem o mundo somente na sua mente e o pensa teoricamente" (HEIDEGGER, 2007, p. 276). É na compreensão da constituição básica do próprio Dasein (o modo de ser do entender-de, como ser-no-mundo) que se deverá buscar a explicação para a realidade. É na primariedade do ocupar-se que se funda a situação das coisas. Num já sempre entender-de abrem-se diferentes possibilidades de entender (possibilidades do Dasein) e delas "procedem os diferentes graus e formas do entender teórico, formas concretas possíveis de entender das ciências" (HEIDEGGER, 2007, p. 324). Do entender-de também dependem todas as demonstrações e argumentações de um conhecimento. As interpretações sempre pressupõem este estar des-coberto na abertura.

Por estar na abertura, o ser humano pode se comportar teoricamente, sua ação se dá nesta abertura do ser. A crítica de Heidegger ao teórico tem a ver com o esquecimento do horizonte do ' $D a$ ', do aí do ser, do ser-no-mundo a partir de onde qualquer teorização é possível. O ser humano está sempre situado, encontra-se num determinado estado, disposto de uma 
ou outra forma compreensivamente no mundo, na lida com os entes, na abertura do ser.

A teorização do Dasein não acontece desligada da sua lida prática situada, de um já sempre encontrar-se no mundo. Ser-no-mundo significa exatamente ser na abertura lidando com o mundo, onde mundo e abertura não são um sem o outro, diferente da consciência e do mundo da filosofia moderna. Não há um Dasein sem mundo, e não há o mundo sem o Dasein, o que resulta num círculo hermenêutico que funciona dentro do horizonte da finitude, que antecipa e permite o encontro com os entes dentro do mundo.

No texto do seminário de $1921 / 22$, Heidegger chama a atenção para que se evite uma avaliação e conclusões rápidas em relação ao sentido do 'prático' sugerido em sua obra. Inclusive os diversos tipos de conhecimento (ciência, filosofia) não podem ser interpretados isoladamente. Como diz Heidegger, "não significa que já se tenha compreendido os respectivos contextos quando se diz: conhecimento tem significação prática (seu objetivo é prático); e conhecimento cresce a partir do contexto prático, seus motivos são práticos" (1985, p. 129). É preciso tomar cuidado com o sentido do prático, para não ser vítima das interpretações tradicionais. As conclusões rápidas sobre a dimensão prática "são exterioridades construídas para trás e para frente com as telhas da construção antiga" (1985, p. 129).

Há, naturalmente, dificuldades para pensar o conhecimento dentro do projeto heideggeriano, tendo em vista a tendência natural de ler e entender tudo a partir do que já se tem, ou seja, da tradição. Mas seu exercício e trabalho de retorno para as condições prévias, para o solo ou fundamento sem fundo donde brota toda teorização, são um desafio para a compreensão do fenômeno do conhecimento. Sua fenomenologia hermenêutica faz aparecerem as condições prévias do conhecimento dos objetos, da pré-compreensão que sustenta o aparecimento e acontecimento dos entes. É no modo histórico, finito, fático do Dasein que essas condições emergem e imprimem ao seu comportamento teórico essas mesmas características. 


\section{Referências bibliográficas}

D’AGOSTINI, Franca. Analíticos e Continentais. São Leopoldo: Unisinos, 2003.

HEIDEGGER, Martin. Ser y Tiempo. Chile: Editorial Universitaria, 1998.

- Prolegómenos para una historia del concepto de tiempo. Madrid: Alianza Editorial, 2007.

- Lógica: la pregunta por la verdade. Madrid: Alianza Editorial, 2004.

. Zur Bestimmung der Philosophie (Sommersemester

1919). Frankfurt am Main: Vittorio Klostermann, 1999.

- Phänomenologische Interpretationen zu Aristoteles

(Wintersemester 1921/22). Frankfurt am Main: Vittorio Klostermann, 1985.

INWOOD, Michael. Heidegger. São Paulo: Loyola, 2004.

STEIN, Ernildo. Pensar é Pensar a Diferença: filosofia e conhecimento empírico. Ijuí: UNIJUÍ, 2002.

- Exercícios de Fenomenologia: limites de um paradigma. Ijuí: UNIJUÍ, 2004.

VON HERRMANN, Friedrich-Wilhelm. Hermeneutik und Reflexion - der Begriff der Phänomenologie bei Heidegger und Husserl. Frankfurt am Main: Vittorio Klostermann, 2000. 